\title{
General advice in ultrasound based elastography of pediatric patients
}

\author{
Christoph F. Dietrich ${ }^{1, *}$, Giovanna Ferraioli ${ }^{2}$, Roxana Sirli ${ }^{3}$, Alina Popescu ${ }^{3}$, Ioan Sporea ${ }^{3}$, \\ Corina Pienar ${ }^{4}$, Christian Kunze ${ }^{5}$, Heike Taut ${ }^{6}$, Simone Schrading $^{7}$, Simona Bota ${ }^{8}$, Dagmar \\ Schreiber-Dietrich ${ }^{1}$, Cheng Fang, ${ }^{9}$, Yi Dong ${ }^{10}$
}

\begin{abstract}
${ }^{1}$ Med. Klinik 2, Caritas-Krankenhaus Bad Mergentheim, Bad Mergentheim, Germany, Department of Clinical Sciences and Infectious Diseases, Fondazione IRCCS Policlinico San Matteo, Medical School University of Pavia, Pavia, Italy, ${ }^{3}$ Department of Gastroenterology and Hepatology, "Victor Babeș" University of Medicine and Pharmacy Timişoara, Romania, ${ }^{4}$ Pediatrics Department, "Victor Babeș" University of Medicine and Pharmacy Timișoara, Romania, ${ }^{5}$ Universitätsklinik und Poliklinik der Martin-Luther-Universität Halle-Wittenberg, Klinik für Radiologie, Abteilung Kinderradiologie, Germany, ${ }^{6}$ Klinik und Poliklinik für Kinder- und Jugendmedizin, Universitäts-klinikum Carl Gustav Carus an der Technischen Universität Dresden, Germany, ${ }^{7}$ Klinik für Diagnostische und Interventionelle Radiologie Aachen, Uniklinikum, RWTH Aachen, Germany, ${ }^{8}$ Department of Internal Medicine and Gastroenterology, Hepatology, Endocrinology, Rheumatology and Nephrology and Emergency Medicine, Klinikum Klagenfurt am Wörthersee, Klagenfurt, Austria, ${ }^{9}$ Department of Radiology. King's College Hospital, London, United Kingdom, ${ }^{10}$ Department of Ultrasound, Zhongshan Hospital, Fudan University, Shanghai, China
\end{abstract}

\begin{abstract}
Ultrasound elastography including transient elastography (TE), point shear wave elastography, (pSWE) and two (three)dimensional shear wave elastography (2D-SWE) have been introduced mainly for the evaluation of the liver. All the techniques are also feasible for the examination of spleen, whereas pSWE and 2D-SWE can be used for the assessment of the pancreas, kidney, gastrointestinal tract and other organs. Strain elastography also plays a role for non-liver applications. The aim of the current report is to highlight unique features and techniques for the elastographic examinations in children and to report initial results in non-liver applications.
\end{abstract}

Keywords: ultrasound; elastography; pediatric; shear wave elastography (SWE)

\section{Introduction}

Ultrasound (US) elastography was introduced into clinical routine more than twenty years ago. Guidelines were published several years later reflecting the updated

Received 03.05.2019 Accepted 02.06.2019

Med Ultrason

2019, Vol. 21, No 3, 316-326

Corresponding author: Prof. Dr. med. Christoph F. Dietrich Medizinische Klinik 2, Caritas-Krankenhaus Uhlandstr. 7, 97980 Bad Mergentheim Tel:+49 7931582201

Email: christoph.dietrich@ckbm.de knowledge of evidence based medicine [1-7]. The most recent update of Guidelines and Recommendations on the Clinical Use of Elastography of the European Federation of Societies for Ultrasound in Medicine and Biology (EFSUMB) and World Federation for Ultrasound in Medicine and Biology (WFUMB) focused on the assessment of diffuse liver disease in adults [6-10]. Compared to adults, fewer publications are available regarding the technical aspects and indications for the use of shear wave elastography in children [11]. The guidelines on adults may not be immediately transferrable to children. In this reviewwe discuss the current evidence on the use of US elastography examination techniques in pediatric patients. 


\section{What is different in liver elastography in children compared to adults?}

An invasive procedure such as liver biopsy is less accepted in children due to the need for general anesthesia, risk of complications and the physical and emotional impact on the child. Non-invasive methods are more suitable, particularly when there is a need for repeated examinations, as in the follow up of patients with chronic liver disease. Elastography is one such method that is feasible and accurate for the assessment of liver fibrosis in adults. However, children are different from adults also in terms of the disease spectrum. In addition, several factors such as age, breath-holding, and probe choice should be taken into consideration regarding the examination technique in children, since they can influence the measurement reproducibility and the diagnostic accuracy in the pediatric population.

\section{Physiological and technical factors}

Age is an important factor as there are physiological differences across pediatric age groups. For instance, in infants the liver is situated lower in the abdomen, with the inferior margin 3-3.5 cm below the costal rim; therefore, the location for measuring liver stiffness may be different. Additionally, younger children are less likely to cooperate compared to an adult in terms of keeping still and holding the breath during the measurement of liver stiffness. They may also not have the patience for the required number of measurements. In a study that measured liver stiffness by transient elastography (TE) in 240 healthy children, Engelmann et al reported $27 \%$ of invalid liver stiffness measurements in children below 6 year-old compared to $9 \%$ in older children [12]. Although breath-holding may affect the technical success rate in children, free breathing has been shown not to affect the variability and agreement of the results [13]. Deep sedation may overcome these technical challenges; however, it can be associated with other adverse effects and it is less accepted by parents. The use of sedation cancels also one of the advantages of US over CT or MR, i.e. the need for sedation with these latter techniques. There are conflicting results in terms of whether normal liver stiffness values differ across different age groups. Normal values of liver stiffness by TE are significantly different among different age groups $(0-5,6-11,12-18$ years) [12].

Although gender has not been shown to influence liver stiffness value in adults, it might have an impact in adolescence, during which there is a "normal" insulin resistance and a higher adiposity in girls. Regarding BMI, country based/WHO growth charts are needed to establish underweight/overweight/obesity status. Dillman et al showed that higher BMI may affect the success rate of liver elastography examination in children [14]. Increased BMI has also been shown to contribute to the likelihood of increased data variability (i.e., increased interquartile range over median) [15].

Finally, several technical points regarding the measurement acquisition should be highlighted. As reported in the adults, significant difference in shear wave velocities were observed between the right and left liver lobe in healthy children [16]. The location for measurement in children has not been established. In adults, measurements in the right liver lobe through intercostal spaces are more reproducible than those in the left liver lobe [17]. Canas et al compared the diagnostic accuracy of liver stiffness measurement by point shear wave elastography (pSWE) (Virtual Touch Quantification - VTQ) in right and left liver lobe to diagnose cystic fibrosis liver disease and found that measurements in the right lobe through the intercostal spaces were significantly more accurate (AUROC 0.746 vs 0.529) [18b]. However, measurements in the right liver may not be possible in children with left lateral liver transplant.

The selection of the probe should be based on anthropometric measurements rather than on age, since patients can be underweight or undeveloped for their age. There are limited and conflicting data regarding the different values obtained with the linear versus the convex probe. In one study evaluating pSWE (VTQ), Fontanilla et al found lower velocity values when using the linear $(1.15 \pm 0.04 \mathrm{~m} / \mathrm{s})$ versus the convex probe $(1.19 \pm 0.04$ $\mathrm{m} / \mathrm{s}$ ), and recommended using the linear probe in children below the age of 12 months 28. For two dimensional(2D) SWE using SuperSonic Shear Imaging (SSI) values, Pienar et al found stiffness values higher with the linear probe than with the convex probe $(7.8 \pm 5.1$ vs $4.1 \pm 0.9$ kPa) [19], whereas Franchi-Abella et al, in their pilot study on 96 children including neonates, found that liver stiffness values were significantly higher when a curvilinear 6-1 MHz transducer was used compared with a linear 15-4 MHz transducer. Amond the 51 healthy children who served as controls, average liver stiffness assessed by 2D-SWE were $5.96+/-1.31 \mathrm{kPa}$ for the SL15-4 probe and $6.94+/-1.42 \mathrm{kPa}$ for the SC6-1 probe $(\mathrm{p}=0.006)$ [20].

\section{The etiologies of diseases}

Although causes of chronic liver diseases in adult such as viral hepatitis (B, C, D), alcohol, NASH, and autoimmune hepatitis are also common etiologies in children, specific etiologies are more likely first detected in the pediatric population such as Cystic Fibrosis Associated Liver Disease (CFLD), metabolic liver diseases, Gaucher's disease, Wilson's disease, $\alpha 1$ antitrypsin deficiency, glycogen storage disease, Niemann-Pick disease, etc. and biliary diseases (biliary atresia, primary sclerosing 
cholangitis etc.).In all these etiologies, US-based liver elastography is indicated for liver fibrosis assessment and follow-up. In addition, it can also be used to assess graft fibrosis after liver transplantation. The mechanisms leading to chronic liver disease in patients with congenital heart disease have been increasingly recognized recently. Corrective surgery, such as the Fontan procedure is associated with progressive hepatic failure and even hepatocellular carcinoma [21]. US-based elastography may be used to diagnose early fibrosis so that cardiac interventions to alleviate hepatic congestion can be attempted.

\section{General technical advice}

\section{Examination technique}

SWE (including TE, pSWE and 2D-SWE) should be performed in a supine position, with the right arm of the patient in extension to increase the width of the intercostal space. The transducer is positioned in a right intercostal space, to visualise the right liver lobe during breath hold, avoiding deep inspiration prior to the breath hold $[1,5]$. A transient breath hold in a neutral position is ideal $[6,7]$. There is little published data on children comparing liver stiffness measurement performed with breath hold and free breathing techniques. Breath hold minimizes measurement variability; however, although breath holding is feasible in older children, in children below the age of 5 years, it is almost impossible. It has been reported that 2D-SWE performed with free-breathing yields results similar to those obtained with breath-holding [20]; thus,

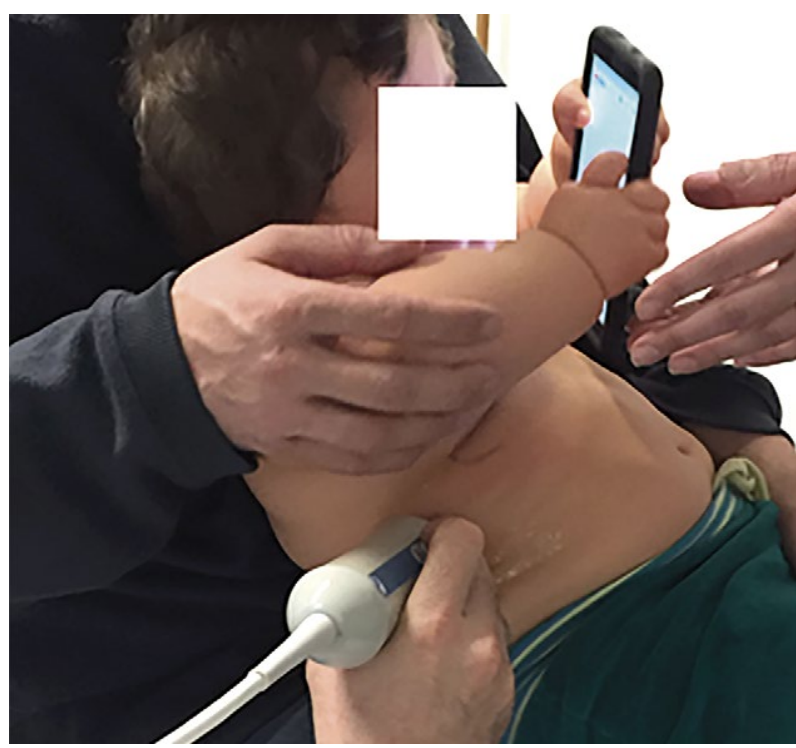

Fig 1. For infants, some tips are a quiet, pediatric friendly environment, positioning them in care giver's arms, use of appropriate age toys for settling (six-month-old boy). in children with suspected liver disease, 2D-SWE measurements are suitable also with free-breathing [22]. The benefit of the free-breathing approach is the substantially shorter time required for the examination, that may decrease further by decreasing the number of acquisitions. No statistically significant influence due to the gender, the location of measurement, or respiratory status on liver elasticity values was observed.

Optimal measurement quality using pSWE or 2D-SWE occurs when the ROI is placed minimum 1-2 $\mathrm{cm}$ [5,23-29] and maximum $6 \mathrm{~cm}$ beneath the liver capsule $[27,28]$. The presence of a parent, and an examiner experienced in performing pediatric examinations will more likely lead to cooperation of the child and successful examination. For infants, some tips are: a quiet, pediatric friendly environment; positioning them in care giver's arms; the use of appropriate age toys or the use of dummies for settling. In older children the use of appropriate music or videos may be helpful (fig 1).

In adults, using the median of 10 measurements from the same location is recommended by the EFSUMB and WFUMB updated guidelines for TE and pSWE examination [6,7]. Three to five measurements are required for 2D-SWE when quality factors are used [6-8]. In the available literature, the number of acquisitions taken in children varies from 1 to 24 [11]. Less than 10 measurements may be required in future studies as excellent reproducibility and accuracy have been reported with a lower number of acquisitions [30]. It has been reported that the number of acquisitions may have little influence on the diagnostic accuracy compared to the variability of the measurements [30]. Therefore, in pediatric studies, the number of measurements taken may be based on the child's age and the cooperation during the examination.

Liver stiffness values can be expressed either in the unit of the Young modulus (kilopascals, $\mathrm{kPa}$ ) when using TE, or in the units of the speed (meters/second, $\mathrm{m} / \mathrm{s}$ ) and $\mathrm{kPa}$ when using pSWE or 2D-SWE, taking into account that the shear wave speed, directly measured by the software in the equipment, is converted to the Young modulus units making some assumptions [1].

\section{Fasting and resting}

In adults, it has been shown that food ingestion increases liver stiffness readings for an estimated 2-3 hours after ingestion [31-33]. Exercise also increases liver stiffness $[6,7,34]$. Measurements should be performed in fasting conditions, ideally overnight and after at least 10 minutes of rest $[6,7]$. However, in babies breastfeeding should not be interrupted, because it causes distress both to the mother and the baby. In bottle fed children, the examination should be performed before the child's next meal, if possible. 


\section{Factors influencing liver stiffness independent of liver fibrosis (confounders)}

There are many confounding factors that need to be taken into account $[6,8,35-47]$. In summary, liver stiffness increases with hepatic necro-inflammation (often, but not exclusively shown by an elevated transaminase level $>5$ times the upper limit of normal), obstructive cholestasis, hepatic congestion, acute hepatitis and infiltrative liver diseases. In addition, general anaesthesia significantly increases liver stiffness in healthy children [11]. Probe choice equally influenced results in paired comparisons, as did food intake and intercurrent, nonhepatological illnesses [48]. It has been reported that, in children with post-transplant liver and without fibrosis, liver stiffness values were significantly higher than those of healthy children with native liver [49]. pSWE measurements show higher reproducibility and minimal data dispersion in patients with a BMI $<30 \mathrm{~kg} / \mathrm{m}^{2}$ compared to the values in patients with a higher BMI [15]. Shear wave velocities by VTQ differed between normal-weight and obese children $(1.08 \pm 0.14$ vs $1.44 \pm 0.39 \mathrm{~m} / \mathrm{s} ; \mathrm{p}<0.001)$, but were not affected by gender. Multivariate linear regression demonstrated shear wave velocity to be primarily associated with age in normal-weight children $\mathrm{p}<0.05$ ) and with BMI in obese children $(\mathrm{p}<0.001)$. In the obese group, mean shear wave velocity was statistically higher in children with abnormal echogenic livers than in those with normal-appearing livers ( $1.53 \pm 0.38$ vs $1.17 \pm 0.27$ ). The difference was not significant in the normal-weight group [50].

\section{Comparison of results between systems in pediatric patients}

There are several sources of variability including technical and patient dependent factors that could affect the comparability between systems. TE is technically feasible in children of all age groups. The upper limit of normal values increases significantly with age. Median values of stiffness are significantly age dependent, while the interquartile range decreased with age $[48,49]$. pSWE was feasible in children at any age with an acceptable reliability. The depth of measurements in the liver had no influence on the results. There was no statistical difference between measurements taken at different ages [51,52]. Conversely, in another study pSWE speed was primarily associated with age, BMI, but not with gender [50]. Other important factors are the transducer's frequency and the operator experience [53-57]. Proprietary elastographic technologies can give different estimates of the shear wave speed within the same liver. Thus, threshold values for fibrosis stages are needed for each specific US system. In addition, studies have also shown that liver stiffness values taken from different commer- cial machines produce different values. Therefore, values taken from different commercial machines are not interchangeable and follow-up studies should be performed using the same machine.

\section{Other applications of elastography}

\section{Spleen}

Conventional US is sensitive in detecting splenic abnormalities such as asplenia, focal (neoplasms, infection etc.) or diffuse (infection, splenomegaly) abnormalities. Splenomegaly can be due to extrasplenic or splenic causes, both causes can induce microscopical changes which lead to changes in spleen elasticity that can be detected with elastography. In order to achieve the most reliable results an optimal setting is essential. During the spleen elastography examination, the patient should be placed in a supine position with the left arm in maximal abduction. The transducer should then be placed on the left intercostal space to provide an adequate acoustic window. It is advisable that the patients hold their breath. This might not be possible in small children; however studies have shown that valid results can be obtained also with free breathing [58]. Convex or linear US probes can be used; the convex probes show higher variability $[58,59]$.

The normal values for children using pSWE (VTQ) are around $2.25 \mathrm{~m} / \mathrm{s}$ [60]. Also, the size of the spleen has an influence on the stiffness values [58,61]. Obesity may reduce the quality of the B-mode US image, but this has not yet been investigated in studies.

Pathological changes of spleen stiffness are seen in patients with liver diseases, systemic diseases and diseases of the bone marrow. Several studies, mostly performed in adults, have shown that increased spleen stiffness is correlated with portal hypertension. In fact, spleen stiffness is more reliable than liver stiffness in detecting variceal bleeding risk in adult patients with clinically significant portal hypertension [62]. Interestingly, spleen stiffness is increased in patients with non-cirrhotic portal hypertension (extrahepatic portal vein obstruction and idiopathic portal hypertension) in whom liver stiffness is normal or only mildly elevated $[63,64]$. This suggests that spleen stiffness and the ratio between liver and spleen stiffness could be used in patients with portal hypertension of unknown origin to help differentiating between cirrhotic and non-cirrhotic causes.

Spleen stiffness value correlates with the stages of liver fibrosis [65]. A study for the prediction of significant varices in children indicated that the TE cut-off value was $38 \mathrm{kPa}$ [61]. Uchida et al suggested that spleen stiffness could also play a role in selecting children with biliary atresia after the Kasai procedure for liver trans- 
plant [66]. In general, systemic diseases that cause splenic inflammation may increase spleen stiffness.

\section{Thyroid}

The adult thyroid has been extensively examined by US techniques [9,67-72] but little is known for the use of US elastography in pediatric patients [73].

Healthy thyroid gland

The mean SWV by pSWE (VTQ) of the normal thyroid gland was $1.22 \pm 0.20 \mathrm{~m} / \mathrm{s}$. There was no correlation between age and the mean SWV (Spearman Rho $=0.049$, $\mathrm{p}=0.556$ ). There was also no correlation between the thyroid gland volume or the whole body surface area and the mean SWV. The only correlation detected was between body surface area and total thyroid gland volume $(\mathrm{p}<0.001)$ [74].

Hashimoto's thyroiditis (HT) and Graves'disease

The mean elastographic strain index (SI) of adult healthy individuals and patients with HT was $0.26 \pm 0.77$ and $1.75 \pm 1.46$, respectively $(\mathrm{p}<0.001)$. For the diagnosis of HT with strain elastography (SE), the sensitivity was $92.1 \%$, and specificity was $66 \%$ when the optimal mean SI cut-off value was $0.31,(p<0.001)$. The use of the SI in patients with HT was highly promising for objective and countable results compared with conventional US. The sensitivity of the increase in SI was determined to be high for the diagnosis of HT. It was also found that the SI had higher sensitivity and specificity than the conventional US in HT patients with moderate to advanced tissue hardening [75]. There is not any published study on the use of elastography in Graves' disease but personal experience shows homogenous intermediate stiffness (fig 2).

Type 1 diabetes mellitus and thyroid gland

Type 1 diabetes mellitus (T1D) affects the thyroid gland stiffness even in patients without autoimmune thyroiditis. The mean SWV in the thyroid gland by pSWE (VTQ) in T1D patients $(1.11 \pm 0.21 \mathrm{~m} / \mathrm{s})$ was lower than that in the control group $(1.29 \pm 0.23 \mathrm{~m} / \mathrm{s})$ and this difference was statistically significant. It has been suggested that pSWE may be a useful method in determining early changes in the thyroid gland in pediatric T1D and may be used as a screening tool [76].

\section{Thyroid gland neoplasia}

Almost all papillary carcinomas are stiff whereas follicular carcinomas may appear soft on elastography $[67,68,70,71]$. All other thyroid malignancies are stiffer than the surrounding tissue. Lymph node metastases are stiff as well [77,78] (fig 3).

\section{Myocardial stiffness}

A pilot study was conducted with the aim to systematically investigate the feasibility of using cardiac SWE in children, and to provide myocardial stiffness control data for cancer patients. The parasternal long-axis (L-A)

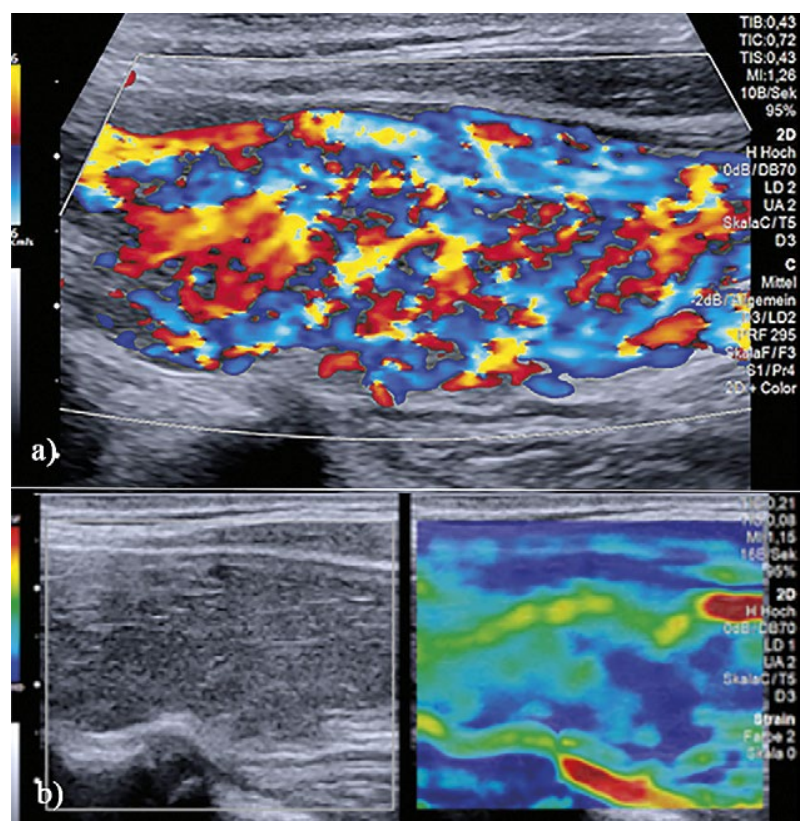

Fig 2. Color- Doppler (a) and Strain Elastography (b): homogeneous hypervascularity (a) and homogeneous intermediate stiffness are the typical features of Graves' disease in children (13 years old boy with clinical signs of hyperthyroidism).

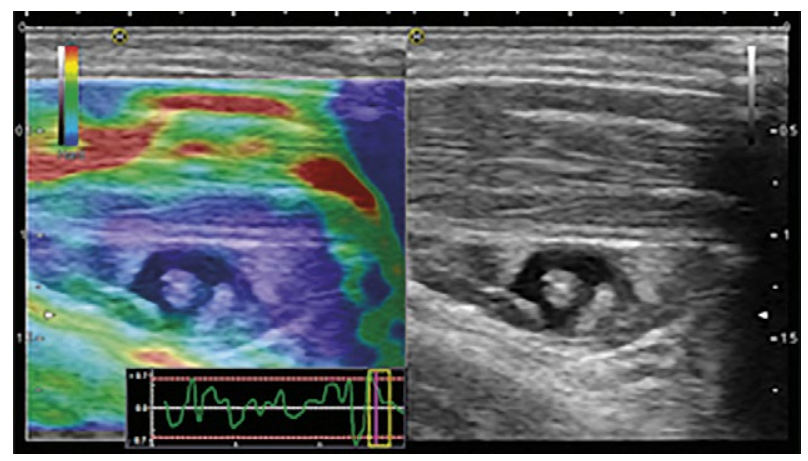

Fig 3. Lymph node metastases of papillary carcinoma in a 15 years old girl assessed by using strain imaging.

and short-axis (S-A) views of the interventricular septum (IVS) were feasible for pediatric cardiac SWE assessment. The L-A and S-A views of the basal and mid IVS provided better success rates than that of the apical IVS. Two-dimensional SWV measurements were 1.26, 1.22, 1.71 and $1.67 \mathrm{~m} / \mathrm{s}$ for L-A base, L-A mid, S-A base and S-A mid IVS, respectively, in healthy children [79].

\section{Muscle stiffness}

pSWE elastography for identifying structural changes, that occur in the spastic muscle after botulinum toxin A injection in children with cerebral palsy, can yield more valuable information with combined use of the modified Ashworth scale [80]. The normal abdominal layers and muscles are shown in figure 4 . 


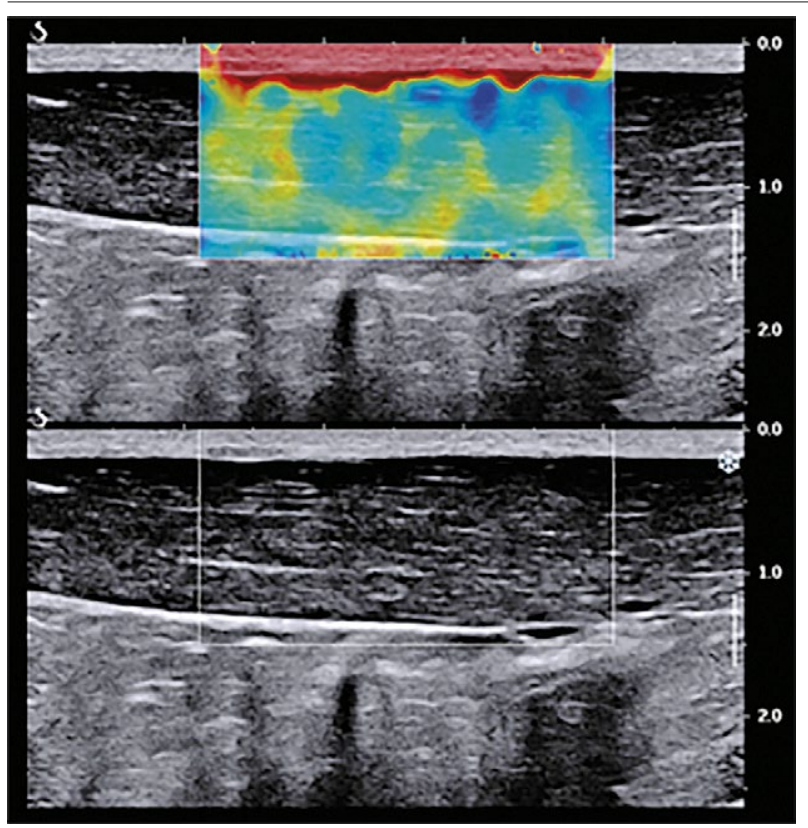

Fig 4. Normal abdominal muscles and layers using strain imaging in a young and slim boy.

\section{Renal parenchyma}

The main causes of chronic kidney disease (CKD) in the pediatric population are renal hypoplasia, dysplasia or an association of both conditions (57.5\% of cases) and vesicoureteral reflux (25.8\%). pSWE (VTQ) values decrease from kidneys with secondary vesicoureteral reflux (6.59 \pm 1.45$)$, to kidneys with primary reflux $(5.3 \pm 1.72)$, to unaffected kidneys contralateral to the reflux $(4.09 \pm 0.97)$ and to normal kidneys (3.13 \pm 0.09$)$ [81].

pSWE seems to have some advantages in predicting pediatric glomerular disease compared to conventional US. Comparisons of SWV measurements between left and right kidneys in the diseased and control groups all showed significant differences. In this case SWV assessment contributed to the early diagnosis of the disease [82].

\section{Gastrointestinal tract}

The gastrointestinal tract has been extensively examined by US techniques in children [77,78,83-86], including the B mode US and color flow imaging. Elastography might play a role in assessing inflammation, fibrosis and infiltration. A correct diagnosis can often only be made by colonoscopy with biopsies or surgery. Elastography would save pediatric patients from invasive procedures in uncertain cases with unclear digestive symptoms $[87,88]$.

Considering that elastography is relatively new in this field, there are currently very few pediatric studies for reference. The latest studies in adults have shown promising ways of applying elastography in Crohn's dis- ease $[83,84,89]$. In order to have comparable values, it is unavoidable to have a standardized setup. There are different kinds of settings, where measurements can be done transdermally or in a trans-rectal endoscopic setting $[53,58,90]$. EUS elastography offers a high resolution of the digestive tract, close view of organs and lymph nodes [91,92]. Elastography techniques have been used in different ways in different studies; dynamic elastography shows promising results while SE has a lower cost, which makes this technique more accessible [73]. The general approach used in normal bowel ultrasonography can also be applied to elastography of the bowel. Elastography should be performed on a patient placed in supine position, with relaxed abdominal muscles. For the study of specific regions, linear probes with high frequencies (7-11 MHz) are recommended [73]. Although it is not necessary in all cases, fasting for 4-6 $\mathrm{h}$ decreases bowel motility. A cup of water might be helpful for the visualization of the duodenum, as well as $250-800 \mathrm{ml}$ polyethylene glycol solution for the terminal ileum, which can be seen after 30 minutes [93].

The diagnosis and monitoring of Crohn's disease represent a diagnostic challenge in which imaging plays an important role [94]. In a pilot study on 48 bowel segments of 14 pediatric patients with Crohn's disease, Fufezan et al showed the reproducibility of the elastography technique [95]. In addition, a study on adult patients with and without appendicitis revealed the benefits of elastography (2D-SWE, SSI). Patients with appendicitis were identified with a sensitivity of $93 \%$, specificity of $100 \%$ considering a $12.5 \mathrm{kPa}$ cut-off value [96]. A statistically significant correlation was found between the intestinal wall hydrosonography changes, presence of complications, activity markers and SE score. SE, along with hydrosonography, represented a reliable investigation for the correct diagnosis and monitoring of pediatric patients with Crohn's disease and the SE score can be used for the assessment of disease activity [95]. Another possible application of elastography is to differentiate colon adenomas from adenocarcinomas. Although adenocarcinomas are rare in the pediatric population, they represent $1 \%$ of all childhood neoplasms [97].

The most important error in SE is due to peristaltic bowel movements, which may give false results. Modern software tries to cancel these errors with correction filters, but a complete success is still not guaranteed [3,94]. At this point in time there are no normal values for these diseases in children. Therefore, further efforts should be made to provide noninvasive diagnostics to the pediatric population.

\section{Postoperative undescended testicles}

2D-SWE was used to determine the testicular volume and elasticity changes in young children with unde- 
scended testes $[98,99]$. pSWE (VTQ) was used to assess the difference in stiffness between scrotally placed testes and postoperative undescended testicles. The SWVs of undescended testicles were $0.75-2.8$ (median, 1.1 ) $\mathrm{m} / \mathrm{s}$, whereas they were $0.65-1$ (median, 0.82 ) $\mathrm{m} / \mathrm{s}$ in healthy controls [100].

\section{Neonatal brain}

Some early reports on the use of transcranial SWE of the periventricular brain parenchyma, in preterm infants and infants with hydrocephalus, suggest that SWE is possible and technically feasible $[101,102]$ (fig 5, fig 6). Albayrak et al showed that differences between brain stiffness values in preterm and term neonates can be demonstrated by using 2D-SWE. Brain stiffness measured from both the thalamus and periventricular white matter were found to be significantly lower in preterm neonates compared with term neonates (cut-off values for determining prematurity less than $8.28 \mathrm{kPa}$ for mean thalamus stiffness and less than $6.59 \mathrm{kPa}$ for periventricular white matter stiffness). The authors suggested that the results might be reference points for evaluating neonatal brain stiffness in research on patients with various illnesses. 2D-SWE also seems to have the ability to depict increased intracranial pressure (ICP) in infants, with a positive linear correlation between SWE values and ICP [102]. Infants with ICP seem to have increased 2D-SWE values (mean $24.2 \pm 5.1 \mathrm{kPa}$ ) compared to healthy infants (mean $14.1 \pm 6.6 \mathrm{kPa}$ ). However, larger prospective studies are still not available. If these preliminary observations of the benefits of transcranial SWE of the neonatal brain will be confirmed by further studies, SWE might be a useful method for additional diagnostic imaging and monitoring in premature infants and children with proven or suspected increased ICP. When performing SWE of the neonatal brain, potential risks and harms of applying high energy levels by US to the neonatal brain should be considered. Recently, an experimental study on mice dealing with the potential biological effects associated with 2D-SWE on the neonatal brain was published [103]. The results indicated that 2D-SWE does not cause detectable histologic changes in the brain of neonatal mice, nor does it have long-term effects on the learning and memory abilities. However, some temporary effects were observed when the scanning lasted for more than $30 \mathrm{~min}$. Thus, it is recommended to pay attention to the scanning duration when assessing neonatal brains with 2D-SWE elastography.

\section{Investigator training}

The examiner should acquire appropriate knowledge and training in US elastography $[104,105]$. The operator

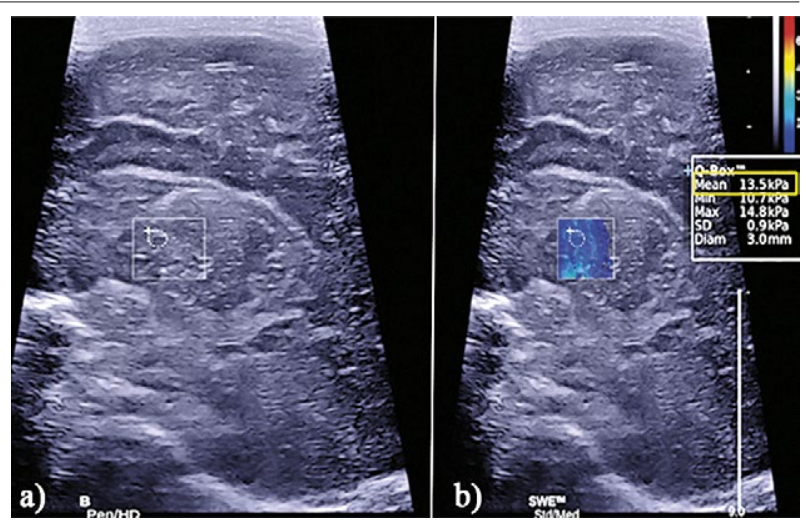

Fig 5. SWE of the neonatal brain in a healthy newborn (14 days old). Sagittal view of the periventricular region in a healthy newborn. B-mode shows no abnormalities (a). 2D-SWE shows a mean periventricular tissue stiffness of $13.5 \mathrm{kPa}$ and a maximum value of $14.8 \mathrm{kPa}(\mathrm{b})$.

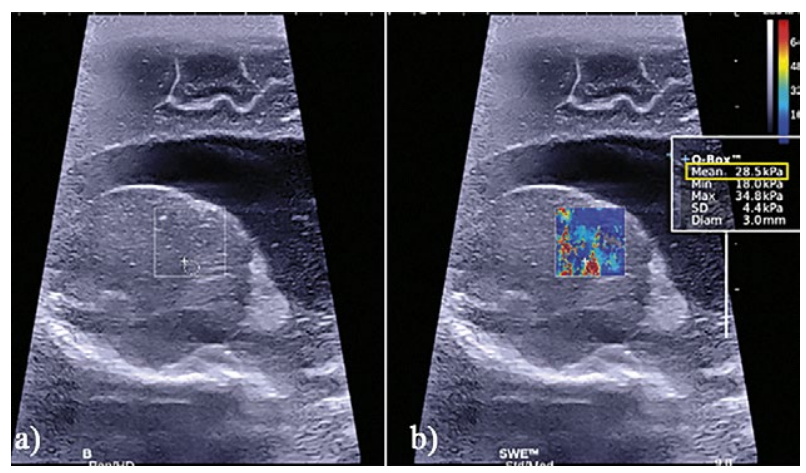

Fig 6. SWE in an 8-week-old, prematurely born infant $\left(30^{\text {th }}\right.$ pregnancy week) with subarachnoid haemorrhage. Sagittal view of the periventricular region. B-mode shows an enlarged lateral ventricle (a). 2D-SWE shows a mean periventricular tissue stiffness of $28.5 \mathrm{kPa}$ and a maximum value of $34.8 \mathrm{kPa}$ (b).

must distinguish a good B mode US image from suboptimal images. In fact, for pSWE and 2D-SWE experience in B-mode US is mandatory. Data acquisition should be undertaken by specialists. Operators experienced both in ultrasonography and elastography are needed to obtain reliable liver stiffness measurements in children, considering the different anatomy, especially in babies (liver situated lower in the abdomen), and the fact that cooperation from a small child is sometimes difficult. The location for measurements can be more difficult to establish in children and here the operator's experience can play a role.

\section{Conflict of interest: none}

Acknowledgment: The authors thank the Bad Mergentheimer Leberzentrum e.V. for support. 


\section{References}

1. Bamber J, Cosgrove D, Dietrich CF, et al. EFSUMB guidelines and recommendations on the clinical use of ultrasound elastography. Part 1: Basic principles and technology. U1traschall Med 2013;34:169-184.

2. Cosgrove D, Piscaglia F, Bamber J, et al. EFSUMB guidelines and recommendations on the clinical use of ultrasound elastography. Part 2: Clinical applications. Ultraschall Med 2013;34:238-253.

3. Shiina T, Nightingale KR, Palmeri ML, et al. WFUMB guidelines and recommendations for clinical use of ultrasound elastography: Part 1: basic principles and terminology. Ultrasound Med Biol 2015;41:1126-1147.

4. Barr RG, Nakashima K, Amy D, et al. WFUMB guidelines and recommendations for clinical use of ultrasound elastography: Part 2: breast. Ultrasound Med Biol 2015;41:11481160.

5. Ferraioli G, Filice C, Castera L, et al. WFUMB guidelines and recommendations for clinical use of ultrasound elastography: Part 3: liver. Ultrasound Med Biol 2015;41:11611179.

6. Dietrich CF, Bamber J, Berzigotti A, et al. EFSUMB Guidelines and Recommendations on the Clinical Use of Liver Ultrasound Elastography, Update 2017 (Long Version). Ultraschall Med 2017;38:e16-e47.

7. Dietrich CF, Bamber J, Berzigotti A, et al. EFSUMB Guidelines and Recommendations on the Clinical Use of Liver Ultrasound Elastography, Update 2017 (Short Version). Ultraschall Med 2017;38:377-394.

8. Ferraioli G, Wong VW, Castera L, et al. Liver Ultrasound Elastography: An Update to the World Federation for Ultrasound in Medicine and Biology Guidelines and Recommendations. Ultrasound Med Biol 2018;44:24192440.

9. Cosgrove D, Barr R, Bojunga J, et al. WFUMB Guidelines and Recommendations on the Clinical Use of Ultrasound Elastography: Part 4. Thyroid. Ultrasound Med Biol 2017;43:4-26.

10. Barr RG, Cosgrove D, Brock M, et al. WFUMB Guidelines and Recommendations on the Clinical Use of Ultrasound Elastography: Part 5. Prostate. Ultrasound Med Biol 2017;43:27-48.

11. Dietrich CF, Sirli R, Ferraioli G, et al. Current knowledge in ultrasound-based liver elastography of pediatric patients. Appl Sci 2018;8:944-963.

12. Engelmann G, Gebhardt C, Wenning D, et al. Feasibility study and control values of transient elastography in healthy children. Eur J Pediatr 2012;171:353-360.

13. Shin HJ, Kim MJ, Kim HY, Roh YH, Lee MJ. Optimal Acquisition Number for Hepatic Shear Wave Velocity Measurements in Children. PLoS One 2016;11:e0168758.

14. Dillman JR, Heider A, Bilhartz JL,et al. Ultrasound shear wave speed measurements correlate with liver fibrosis in children. Pediatr Radiol 2015;45:1480-1488.

15. Trout AT, Dillman JR, Xanthakos S, et al. Prospective Assessment of Correlation between US Acoustic Radiation
Force Impulse and MR Elastography in a Pediatric Population: Dispersion of US Shear-Wave Speed Measurement Matters. Radiology 2016;281:544-552.

16. Matos H, Trindade A, Noruegas MJ. Acoustic radiation force impulse imaging in paediatric patients: normal liver values. J Pediatr Gastroenterol Nutr 2014;59:684-688.

17. Jaffer OS, Lung PF, Bosanac D, et al. Acoustic radiation force impulse quantification: repeatability of measurements in selected liver segments and influence of age, body mass index and liver capsule-to-box distance. Br J Radiol 2012;85:e858-e863.

18. Canas T, Macia A, Munoz-Codoceo RA, et al. Hepatic and Splenic Acoustic Radiation Force Impulse Shear Wave Velocity Elastography in Children with Liver Disease Associated with Cystic Fibrosis. Biomed Res Int 2015;2015:517369.

18b. Fontanilla T, Canas T, Macia A, et al. Normal values of liver shear wave velocity in healthy children assessed by acoustic radiation force impulse imaging using a convex probe and a linear probe. Ultrasound Med Biol 2014;40:470-477

19. Pienar C, Velea PI, Ciuca I, et al. P181 Two dimensional shear wave elastography in children: linear versus convex probe. Arch Dis Child 2017;102:A104.

20. Franchi-Abella S, Corno L, Gonzales E, et al. Feasibility and Diagnostic Accuracy of Supersonic Shear-Wave Elastography for the Assessment of Liver Stiffness and Liver Fibrosis in Children: A Pilot Study of 96 Patients. Radiology 2016;278:554-562.

21. Kutty SS, Zhang M, Danford DA, et al. Hepatic stiffness in the bidirectional cavopulmonary circulation: The Liver Adult-Pediatric-Congenital-Heart-Disease Dysfunction Study group. J Thorac Cardiovasc Surg 2016;151:678-684.

22. Jung $C$, Groth M, Petersen KU, et al. Hepatic shear wave elastography in children under free-breathing and breathhold conditions. Eur Radiol 2017;27:5337-5343.

23. Liao LY, Kuo KL, Chiang HS, Lin CZ, Lin YP, Lin CL. Acoustic radiation force impulse elastography of the liver in healthy patients: test location, reference range and influence of gender and body mass index. Ultrasound Med Biol 2015;41:698-704.

24. Goertz RS, Egger C, Neurath MF, Strobel D. Impact of food intake, ultrasound transducer, breathing maneuvers and body position on acoustic radiation force impulse (ARFI) elastometry of the liver. Ultraschall Med 2012;33:380-385.

25. Goertz RS, Zopf Y, Jugl V, et al. Measurement of liver elasticity with acoustic radiation force impulse (ARFI) technology: an alternative noninvasive method for staging liver fibrosis in viral hepatitis. Ultraschall Med 2010;31:151155.

26. Sporea I, Sirli RL, Deleanu A, et al. Acoustic radiation force impulse elastography as compared to transient elastography and liver biopsy in patients with chronic hepatopathies. U1traschall Med 2011;32:S46-S52.

27. Wang CZ, Zheng J, Huang ZP, et al. Influence of measurement depth on the stiffness assessment of healthy liver with real-time shear wave elastography. Ultrasound Med Biol 2014;40:461-469. 
28. Procopet B, Berzigotti A, Abraldes JG, et al. Real-time shear-wave elastography: applicability, reliability and accuracy for clinically significant portal hypertension. J Hepatol 2015;62:1068-1075.

29. Barr RG, Ferraioli G, Palmeri ML, et al. Elastography Assessment of Liver Fibrosis: Society of Radiologists in Ultrasound Consensus Conference Statement. Radiology 2015;276:845-861.

30. Fang C, Jaffer OS, Yusuf GT, et al. Reducing the Number of Measurements in Liver Point Shear-Wave Elastography: Factors that Influence the Number and Reliability of Measurements in Assessment of Liver Fibrosis in Clinical Practice. Radiology 2018;287:844-852.

31. Mederacke I, Wursthorn K, Kirschner J, et al. Food intake increases liver stiffness in patients with chronic or resolved hepatitis C virus infection. Liver Int 2009;29:1500-1506.

32. Arena U, Lupsor Platon M, Stasi C, et al. Liver stiffness is influenced by a standardized meal in patients with chronic hepatitis $\mathrm{C}$ virus at different stages of fibrotic evolution. Hepatology 2013;58:65-72.

33. Berzigotti A, De Gottardi A, Vukotic R, et al. Effect of meal ingestion on liver stiffness in patients with cirrhosis and portal hypertension. PLoS One 2013;8:e58742.

34. Gersak MM, Sorantin E, Windhaber J, Dudea SM, Riccabona $\mathrm{M}$. The influence of acute physical effort on liver stiffness estimation using Virtual Touch Quantification (VTQ). Preliminary results. Med Ultrason 2016;18:151-156.

35. Coco B, Oliveri F, Maina AM, et al. Transient elastography: a new surrogate marker of liver fibrosis influenced by major changes of transaminases. J Viral Hepat 2007;14:360-369.

36. Sagir A, Erhardt A, Schmitt M, Haussinger D. Transient elastography is unreliable for detection of cirrhosis in patients with acute liver damage. Hepatology 2008;47:592595.

37. Arena U, Vizzutti F, Corti G, et al. Acute viral hepatitis increases liver stiffness values measured by transient elastography. Hepatology 2008;47:380-384.

38. Vigano M, Massironi S, Lampertico P, et al. Transient elastography assessment of the liver stiffness dynamics during acute hepatitis B. Eur J Gastroenterol Hepatol 2010;22:180184.

39. Millonig G, Reimann FM, Friedrich S, et al. Extrahepatic cholestasis increases liver stiffness (FibroScan) irrespective of fibrosis. Hepatology 2008;48:1718-1723.

40. Millonig G, Friedrich S, Adolf S, et al. Liver stiffness is directly influenced by central venous pressure. J Hepatol 2010;52:206-210.

41. Mueller S, Millonig G, Sarovska L, et al. Increased liver stiffness in alcoholic liver disease: differentiating fibrosis from steatohepatitis. World J Gastroenterol 2010;16:966972.

42. Trabut JB, Thepot V, Nalpas B, et al. Rapid decline of liver stiffness following alcohol withdrawal in heavy drinkers. Alcohol Clin Exp Res 2012;36:1407-1411.

43. Bardou-Jacquet E, Legros L, Soro D, et al. Effect of alcohol consumption on liver stiffness measured by transient elastography. World J Gastroenterol 2013;19:516-522.
44. Thiele M, Detlefsen S, Sevelsted Moller L, et al. Transient and 2-Dimensional Shear-Wave Elastography Provide Comparable Assessment of Alcoholic Liver Fibrosis and Cirrhosis. Gastroenterology 2016;150:123-133.

45. Cassinotto C, Boursier J, De Ledinghen V, et al. Liver stiffness in nonalcoholic fatty liver disease: A comparison of Supersonic Shear Imaging, FibroScan and ARFI with liver biopsy. Hepatology 2016;63:1817-1827.

46. Zeng J, Liu GJ, Huang ZP, et al. Diagnostic accuracy of twodimensional shear wave elastography for the non-invasive staging of hepatic fibrosis in chronic hepatitis B: a cohort study with internal validation. Eur Radiol 2014;24:25722581.

47. Cassinotto C, Lapuyade B, Mouries A, et al. Noninvasive assessment of liver fibrosis with impulse elastography: comparison of Supersonic Shear Imaging with ARFI and Fibroscan. J Hepatol 2014;61:550-557.

48. Lewindon PJ, Balouch F, Pereira TN, et al. Transient liver elastography in unsedated control children: Impact of age and intercurrent illness. J Paediatr Child Health 2016;52:637-642.

49. Goldschmidt I, Streckenbach C, Dingemann C, et al. Application and limitations of transient liver elastography in children. J Pediatr Gastroenterol Nutr 2013;57:109-113.

50. Bailey SS, Youssfi M, Patel M, Hu HH, Shaibi GQ, Towbin RB. Shear-wave ultrasound elastography of the liver in normal-weight and obese children. Acta Radiol 2017:58:15111518.

51. Hanquinet S, Courvoisier D, Kanavaki A, Dhouib A, Anooshiravani M. Acoustic radiation force impulse imagingnormal values of liver stiffness in healthy children. Pediatr Radiol 2013;43:539-544.

52. Eiler J, Kleinholdermann U, Albers D, et al. Standard value of ultrasound elastography using acoustic radiation force impulse imaging (ARFI) in healthy liver tissue of children and adolescents. Ultraschall Med 2012;33:474-479.

53. Guzmán-Aroca F, Reus M, Berná-Serna JD, et al. Reproducibility of shear wave velocity measurements by acoustic radiation force impulse imaging of the liver: a study in healthy volunteers. J Ultrasound Med 2011;30:975979.

54. D’Onofrio M, Gallotti A, Mucelli RP. Tissue quantification with acoustic radiation force impulse imaging: Measurement repeatability and normal values in the healthy liver. AJR Am J Roentgenol 2010;195:132-136.

55. Ferraioli G, Tinelli C, Lissandrin R, et al. Point shear wave elastography method for assessing liver stiffness. World J Gastroenterol 2014;20:4787-4796.

56. Ma JJ, Ding H, Mao F, Sun HC, Xu C, Wang WP. Assessment of liver fibrosis with elastography point quantification technique in chronic hepatitis B virus patients: a comparison with liver pathological results. J Gastroenterol Hepatol 2014;29:814-819.

57. Fraquelli M, Baccarin A, Casazza G, et al. Liver stiffness measurement reliability and main determinants of point shear-wave elastography in patients with chronic liver disease. Aliment Pharmacol Ther 2016;44:356-365. 
58. Mazur R, Celmer M, Silicki J, Holownia D, Pozowski P, Miedzybrodzki K. Clinical applications of spleen ultrasound elastography - a review. J Ultrason 2018;18:37-41.

59. Canas T, Fontanilla T, Miralles M, Macia A, Malalana A, Roman E. Normal values of spleen stiffness in healthy children assessed by acoustic radiation force impulse imaging (ARFI): comparison between two ultrasound transducers. Pediatr Radiol 2015;45:1316-1322.

60. Lee MJ, Kim MJ, Han KH, Yoon CS. Age-related changes in liver, kidney, and spleen stiffness in healthy children measured with acoustic radiation force impulse imaging. Eur J Radiol 2013;82:e290-e294.

61. Sutton H, Fitzpatrick E, Davenport M, et al. Transient Elastography Measurements of Spleen Stiffness as a Predictor of Clinically Significant Varices in Children. J Pediatr Gastroenterol Nutr 2018;67:446-451.

62. Berzigotti A, Ferraioli G, Bota S, Gilja OH, Dietrich CF. Novel ultrasound-based methods to assess liver disease: The game has just begun. Dig Liver Dis 2018;50:107-112.

63. Sharma P, Kirnake V, Tyagi P, et al. Spleen stiffness in patients with cirrhosis in predicting esophageal varices. Am J Gastroenterol 2013;108:1101-1107.

64. Seijo S, Reverter E, Miquel R, et al. Role of hepatic vein catheterisation and transient elastography in the diagnosis of idiopathic portal hypertension. Dig Liver Dis 2012;44:855-860.

65. Chen SH, Li YF, Lai HC, et al. Noninvasive assessment of liver fibrosis via spleen stiffness measurement using acoustic radiation force impulse sonoelastography in patients with chronic hepatitis B or C. J Viral Hepat 2012;19:654-663.

66. Uchida H, Sakamoto S, Kobayashi M, et al. The degree of spleen stiffness measured on acoustic radiation force impulse elastography predicts the severity of portal hypertension in patients with biliary atresia after portoenterostomy. J Pediatr Surg 2015;50:559-564.

67. Dighe M, Barr R, Bojunga J, et al. Thyroid Ultrasound: State of the Art Part 1 - Thyroid Ultrasound reporting and Diffuse Thyroid Diseases. Med Ultrason 2017;19:79-93.

68. Dighe M, Barr R, Bojunga J, et al. Thyroid Ultrasound: State of the Art. Part 2 - Focal Thyroid Lesions. Med Ultrason 2017;19:195-210.

69. Dietrich CF, Muller T, Bojunga J, et al. Statement and Recommendations on Interventional Ultrasound as a Thyroid Diagnostic and Treatment Procedure. Ultrasound Med Biol 2018;44:14-36.

70. Dietrich CF, Bojunga J. Ultrasound of the Thyroid. Laryngorhinootologie 2016;95:87-104.

71. Friedrich-Rust M, Vorlaender C, Dietrich CF, et al. Evaluation of Strain Elastography for Differentiation of Thyroid Nodules: Results of a Prospective DEGUM Multicenter Study. Ultraschall Med 2016;37:262-270.

72. Chan HW, Pressler R, Uff C, et al. A novel technique of detecting MRI-negative lesion in focal symptomatic epilepsy: intraoperative ShearWave elastography. Epilepsia 2014;55:e30-e33.

73. Dietrich CF, Barr RG, Farrokh A, et al. Strain Elastography - How To Do It? Ultrasound Int Open 2017;3:E137-E149.
74. Ceyhan Bilgici M, Saglam D, Delibalta S, Yucel S, Tomak L, Elmali M. Shear wave velocity of the healthy thyroid gland in children with acoustic radiation force impulse elastography. J Med Ultrason (2001) 2018;45:75-80.

75. Ozturk M, Yildirim R. The usefulness of strain wave elastography in the diagnosis and grading of Hashimoto's thyroiditis in children. Radiol Med 2017;122:960-966.

76. Saglam D, Ceyhan Bilgici M, Kara C, Can Yilmaz G, Tanrivermis Sayit A. Does Type 1 Diabetes Mellitus Affect the Shear Wave Velocity of the Thyroid Gland of Children Without Autoimmune Thyroiditis? Ultrasound Q 2017;33:225-228.

77. Chiorean L, Barr RG, Braden B, et al. Transcutaneous Ultrasound: Elastographic Lymph Node Evaluation. Current Clinical Applications and Literature Review. Ultrasound Med Biol 2016;42:16-30.

78. Chiorean L, Cui XW, Klein SA, et al. Clinical value of imaging for lymph nodes evaluation with particular emphasis on ultrasonography. Z Gastroenterol 2016;54:774-790.

79. Song P, Bi X, Mellema DC, et al. Pediatric Cardiac Shear Wave Elastography for Quantitative Assessment of Myocardial Stiffness: A Pilot Study in Healthy Controls. Ultrasound Med Biol 2016;42:1719-1729.

80. Ceyhan Bilgici M, Bekci T, Ulus Y, Bilgici A, Tomak L, Selcuk MB. Quantitative assessment of muscle stiffness with acoustic radiation force impulse elastography after botulinum toxin A injection in children with cerebral palsy. J Med Ultrason (2001) 2018;45:137-141.

81. Bruno C, Caliari G, Zaffanello M, et al. Acoustic radiation force impulse (ARFI) in the evaluation of the renal parenchymal stiffness in paediatric patients with vesicoureteral reflux: preliminary results. Eur Radiol 2013;23:3477-3484.

82. Xu B, Jiang G, Ye J, He J, Xie W. Research on pediatric glomerular disease and normal kidney with shear wave based elastography point quantification. Jpn J Radiol 2016;34:738-746.

83. Schreiber-Dietrich D, Chiorean L, Cui XW, et al. Particularities of Crohn's disease in pediatric patients: current status and perspectives regarding imaging modalities. Expert Rev Gastroenterol Hepatol 2015;9:1313-1325.

84. Chiorean L, Schreiber-Dietrich D, Braden B, et al. Ultrasonographic imaging of inflammatory bowel disease in pediatric patients. World J Gastroenterol 2015;21:52315241.

85. Nylund K, Maconi G, Hollerweger A, et al. EFSUMB Recommendations and Guidelines for Gastrointestinal Ultrasound - Part 1: Examination Techniques and Normal Findings (Long version). Ultraschall Med 2017;38:e1-e15.

86. Nylund K, Maconi G, Hollerweger A, et al. EFSUMB Recommendations and Guidelines for Gastrointestinal Ultrasound - Part 1: Examination Techniques and Normal Findings (Short version). Ultraschall Med 2017;38:273-284.

87. Hall JE. Guyton and Hall Textbook of Medical Physiology. 12th Ed. Saunders 2010.

88. Dietrich CF, Viel K, Braden B, Caspary WF, Zeuzem S. Mediastinal lymphadenopathy: an extrahepatic manifestation of chronic hepatitis C? Z Gastroenterol 2000;38:143-152. 
89. Dong Y, Braden B, Klinger C, Ripolles T, Dietrich CF. Ultrasound findings in extragenital endometriosis. J Ultrason 2018;18:247-254.

90. Dietrich CF, Bibby E, Jenssen C, Saftoiu A, Iglesias-Garcia J, Havre RF. EUS elastography: How to do it? Endosc U1trasound 2018;7:20-28.

91. Hocke M, Braden B, Jenssen C, Dietrich CF. Present status and perspectives of endosonography 2017 in gastroenterology. Korean J Intern Med 2018;33:36-63.

92. Cui XW, Chang JM, Kan QC, Chiorean L, Ignee A, Dietrich CF. Endoscopic ultrasound elastography: Current status and future perspectives. World J Gastroenterol 2015;21:13212-13224.

93. Nowicki A, Dobruch-Sobczak K. Introduction to ultrasound elastography. J Ultrason 2016;16:113-124.

94. Branchi F, Caprioli F, Orlando S, Conte D, Fraquelli M. Non-invasive evaluation of intestinal disorders: The role of elastographic techniques. World J Gastroenterol 2017;23: 2832-2840.

95. Fufezan O, Asavoaie C, Tamas A, Farcau D, Serban D. Bowel elastography - a pilot study for developing an elastographic scoring system to evaluate disease activity in pediatric Crohn's disease. Med Ultrason 2015;17:422-430.

96. Cha SW, Kim IY, Kim YW. Quantitative measurement of elasticity of the appendix using shear wave elastography in patients with suspected acute appendicitis. PLoS One 2014;9:e101292.

97. Koh KJ, Lin LH, Huang SH, Wong JU. CARE--pediatric colon adenocarcinoma: a case report and literature review comparing differences in clinical features between children and adult patients. Medicine (Baltimore) 2015;94:e503.
98. Ucar AK, Alis D, Samanci C, et al. A preliminary study of shear wave elastography for the evaluation of unilateral palpable undescended testes. Eur J Radiol 2017;86:248-251.

99. Shin HJ, Lee YS, Yoon H, et al. Testicular volume and elasticity changes in young children with undescended testes. Med Ultrason 2017;19:380-385.

100. Hattapoglu S, Goya C, Arslan S, et al. Evaluation of postoperative undescended testicles using point shear wave elastography in children. Ultrasonics 2016;72:191-194.

101. Albayrak E, Kasap T. Evaluation of Neonatal Brain Parenchyma Using 2-Dimensional Shear Wave Elastography. J Ultrasound Med 2018;37:959-967.

102. Meiser N, Panek A, Treppels-Kottek S, Orlikowsky T, Kuhl C, Schrading S. Einsatz der Scherwellen Elastografie (SWE) zur Beurteilung intrakranieller Druckverhältnisse bei gesunden Säuglingen und Säuglingen mit Hydrocephalus - eine Machbarkeitsstudie. ROFO 2017;189:S1-S124.

103. Li C, Zhang C, Li J, Cao X, Song D. An Experimental Study of the Potential Biological Effects Associated with 2-D Shear Wave Elastography on the Neonatal Brain. U1trasound Med Biol 2016;42:1551-1559.

104. Sidhu PS, Cantisani V, Dietrich CF, et al. The EFSUMB Guidelines and Recommendations for the Clinical Practice of Contrast-Enhanced Ultrasound (CEUS) in Non-Hepatic Applications: Update 2017 (Short Version). Ultraschall Med 2018;39:154-180.

105. Sidhu PS, Cantisani V, Dietrich CF, et al. The EFSUMB Guidelines and Recommendations for the Clinical Practice of Contrast-Enhanced Ultrasound (CEUS) in Non-Hepatic Applications: Update 2017 (Long Version). Ultraschall Med 2018;39:e2-e44. 